\title{
Treatment of Auricular Deformities with the EarWell Sys- tem in Three Newborns
}

Ji Hee Kim, M.D., Youn Ho Sheen, MD., Ki Eun Kim, M.D., Ju Sun Heo, M.D., Ji Hyun Jeon, M.D., and Sung Hoon Chung, M.D.*

Department of Pediatrics, CHA Gangnam Medical Center, CHA University School of Medicine, Seoul, Korea

Department of Pediatrics*, Kyung Hee University Hospital at Gangdong, Kyung Hee University School of Medicine, Seoul, Korea

\section{ABSTRACT}

Auricular deformities occur frequently in newborn infants. Typically, most pediatricians explain to parents that these deformities will get better as child grows older. But, only about $30 \%$ of auricular deformities are known to be self-correcting, and there is no reliable model to predict them. If ear molding is initiated during the first days of life with the EarWell System, successful treatment could be possible without pain in a non-surgical way. We present 3 cases of auricular deformities treated with the EarWell System. 2 infants were born with auricular deformities at Gangnam Cha Medical Center and 1 infant visited the outpatient clinic for the treatment of auricular deformities. 5 ears in 3 infants underwent ear molding using the EarWell System. They had it placed on the 20th day after birth. Average treatment time was 18.7 days, and all of them were corrected. Complications were redness, oozing, erosion and mild pressure ulcerations. Early recognition and treatment of the auricular deformity ensure the great prospect of success. Also, it is important for both the parents and the pediatricians to know that auricular deformities could be successfully treated with Earwell System.

Key Words: Auricular deformity, Newborn infants, EarWell system

\section{서론}

신생아에서 귓바퀴 기형은 흔하다. 대부분의 의사들은 부모에게 이러한 기형들은 아이가 자 라면서 저절로 좋아질 것이라고 설명한다. 하지만, 신생아 귀 기형의 약 $30 \%$ 정도만 저절로 호 전되며 그 외에는 저절로 호전되지 않기 때문에 수술이 가능한 4-5세까지 기형을 가지고 살아 가게 된다 ${ }^{1-3)}$. 어떤 임상의도 귀 기형이 자연적으로 호전될 것이라는 것을 예측할 수 없다.

최근에는 여러 나라에서 많은 신생아 귓바퀴 기형을 치료하는데 EarWell System (Becon Medical Ltd., Naperville, IL, USA)이라는 귓바퀴 교정기를 사용하고 있다. EarWell System은 생후 3 주 이내 신생아 귓바퀴 기형을 비수술적인 방법으로 교정하는 교정 장치이다. 귓바퀴 기형이 있 는 신생아에서 EarWell System으로 치료 후 정상 귓바퀴 모양으로 바뀐 3례를 보고하고자 한다.
Received: 4 April 2017

Revised: 21 July 2017

Accepted: 25 July 2017

Correspondence to: Sung Hoon

Chung

Department of Pediatrics, Kyung Hee University Hospital at Gangdong, 149 Sangil-dong, Gangdong-gu, Seoul 05278, Korea Tel: $+82-2-440-6130$

Fax: +82-2-440-7175

E-mail:pedc@daum.net

Copyright(c)

By Korean Society of Neonatology.

All right reserved.

This is an Open-Access article distributed under the terms of the Creative Commons Attribution Non-Commercial License (http://creativecommons.org/licenses/ by-nc/4.0), which permits unrestricted non-commercial use, distribution, and reproduction in any medium, provided the original work is properly cited. 
증례

\section{1. 증례 1}

재태기간 38 주 4 일, 출생 체중 $3.05 \mathrm{~kg}$, 제왕절개로 본원에서 출 생한 여아였다. 출생 시 신생아실에서 시행한 이학적 소견상 오른쪽 귓바퀴 중 귀둘레 모양 이상 외에 다른 소견은 관찰되지 않았다. 생 후 20 일, 외래 추적 관찰 결과 오른쪽 귀둘레의 모양이 저절로 교정 되지 않아 EarWell System으로 교정을 시작하기로 하였다.

EarWell System 장치는 크래들 세트(cradle set), 미니 견인기, 외 이 former, 리테이너 테이프의 4가지로 구성되어 있다(Figure 1A). 한 번 사용한 제품은 재사용하지 않았다. 치료 방법은 1단계, 귀 주 위의 머리카락을 잘라낸다. 2 단계, 알코올 솜으로 피부를 깨끗이 닦 아낸다. 3 단계, 뒤쪽 크래들을 장착한다. (1) 크래들 안쪽으로 귀를 집어 넣고 두피에 임시로 고정한다. (2) 귀를 들어 올려서 신생아 귀 의 귀 뒤 고랑부분이 posterior conformer에 위치하도록 한다. (3) posterior conformer 는 귀의 중간 위쪽 부분에 위치해야 하며, 귓바 퀴 테두리를 덮을 수 있도록 하고 귀 뒤 고랑에서 1-2 mm 떨어진 지 점에 평행하게 위치해야 한다. (4)마지막으로 뒤쪽 크래들 바닥면에 붙여진 테이프를 제거하고 두피 쪽 피부에 단단히 고정한다. 4단계, 견인기(retractor)를 장착한다. 5단계, 외이 former를 장착한다. 6단 계, 앞쪽 크래들을 장착한다 ${ }^{4)}$ (Figure 1B). 교정기 부착 후 $3 \mathrm{M}$ 테이 프로 윗부분을 ‘'자로 부착하여 고정을 단단히 시킨다. 물, 모유 혹 은 분유, 구토로 인해 오염되었을 경우 알코올로 깨끗이 세척한 후 시술자에 의해 다시 고정하도록 한다. 관리 및 부작용에 대해서 부 모에게 설명하고 부작용이 생기면 즉시 시술 의사의 진료를 받고 치 료 및 교정기 지속 착용 여부에 대하여 상의하도록 하였다.

이 환자는 2 주 착용 후 미란, 진물, $2 \times 3 \mathrm{~mm}$ 궤양으로 인해 치료 를 멈추고 교정기를 제거하였다. 교정기 제거 방법으로 1단계, 앞쪽 크래들을 제거하고, 2 단계, 외이 former를 제거하였으며, 3 단계, 견 인기를 제거하였고, 4 단계, 뒤쪽 크래들을 제거하였다 ${ }^{4)}$. 제거 후 이 전 귀둘레 모양 이상이 정상 모양으로 교정된 것을 확인하였다(Fig- ure 2A). 5일 동안 국소 항생제 연고 치료를 시행한 후 염증 소견과 궤양은 호전되었다. 교정된 모양이 잘 유지되어 교정기 치료는 더 이상 진행하지 않았고 리테이너 테이프를 2주 동안 착용하도록 하 였다.

\section{2. 증례 2}

재태기간 38 주 6 일, 출생 체중 $3.46 \mathrm{~kg}$, 제왕절개로 본원에서 출생 한 남아였다. 출생 시 신생아실에서 시행한 이학적 소견상 양쪽 귓 바퀴의 귀둘레가 두껍고 컵 모양 귀의 형태를 보였다. 그 외 다른 이 상 소견은 관찰되지 않았다. 생후 20 일 후 외래 추적 관찰 결과 양쪽 귓바퀴 기형이 저절로 교정되지 않고 왼쪽 접힌 귀는 증상이 점점 악화되는 소견을 보여 EarWell System으로 교정을 시작하였다. 1주 일 후 외래 추적 관찰 시 귓바퀴 뒤 발적과 진물이 약간 있었으나 궤 양은 관찰되지 않아 국소 항생제 연고를 1회 바르고 교정기를 그대 로 유지하기로 하였다. 장착 2 주 후 추적 관찰 시에는 귓바퀴 뒤 진 물은 더 이상 관찰되지 않았으며 귓바퀴 모양도 정상모양으로 교정 이 잘 되고 있어 1 주일 더 장착한 후 제거와 동시에 치료를 마쳤다 (Figure 2B).

\section{3. 증례 3}

재태기간 39주 4 일, 출생 체중 $3.48 \mathrm{~kg}$, 정상 분만으로 외부 병원 에서 출생한 남아였다. 생후 20 일째 처음 내원하였으며 오른쪽 귀는 귓바퀴 테두리 이상, 왼쪽 귀는 접힌 귀 양상을 보였으며 다른 이상 소견은 없었다. 보호자에게 시술 과정 및 부작용을 설명하였고 교정 기 장착 동의서를 받은 후 EarWell System으로 교정을 시작하였다. 장착 2주 후 추적 관찰 시 교정기 주위 피부 부작용은 관찰되지 않았 으며 귓바퀴 모양도 정상모양으로 교정이 잘 되고 있어 1 주일 더 장 착한 후 제거와 동시에 치료를 마쳤다(Figure 2C).

세 환자의 EarWell System 장착 방법은 동일했다. 우선 귀 교정기 가 부착될 부분 주위의 머리카락을 잘라낸 후 알코올 솜으로 피부를 깨끗이 닦고 뒤쪽 크래들을 장착하였다. 견인기는 귓바퀴 테두리의

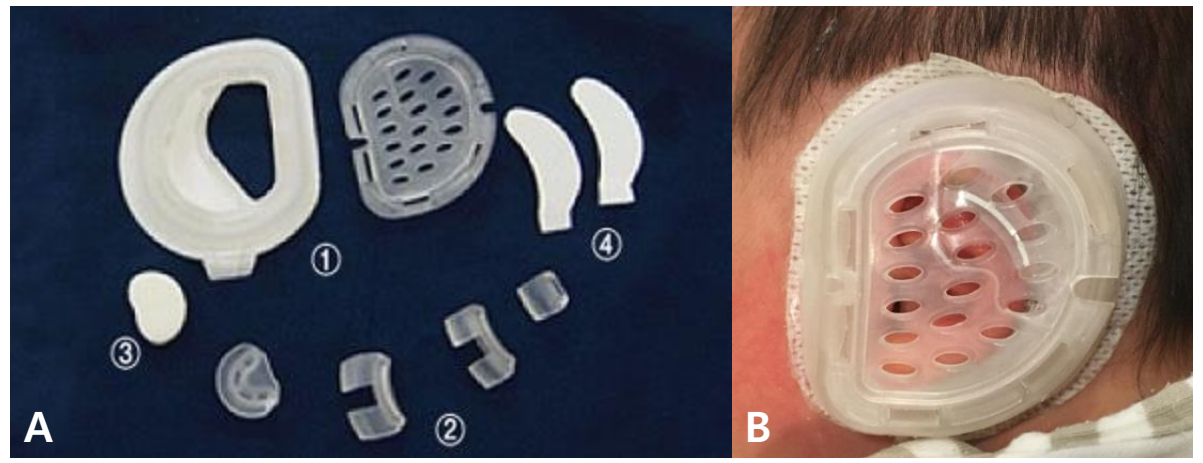

Figure 1. (A) The EarWell System is composed of (1) an anterior (cap) and posterior cradle, (2) retractor, (3) a conchal former and (4) retainer tape. (B) A newborn infant with the EarWell System in place. 
A
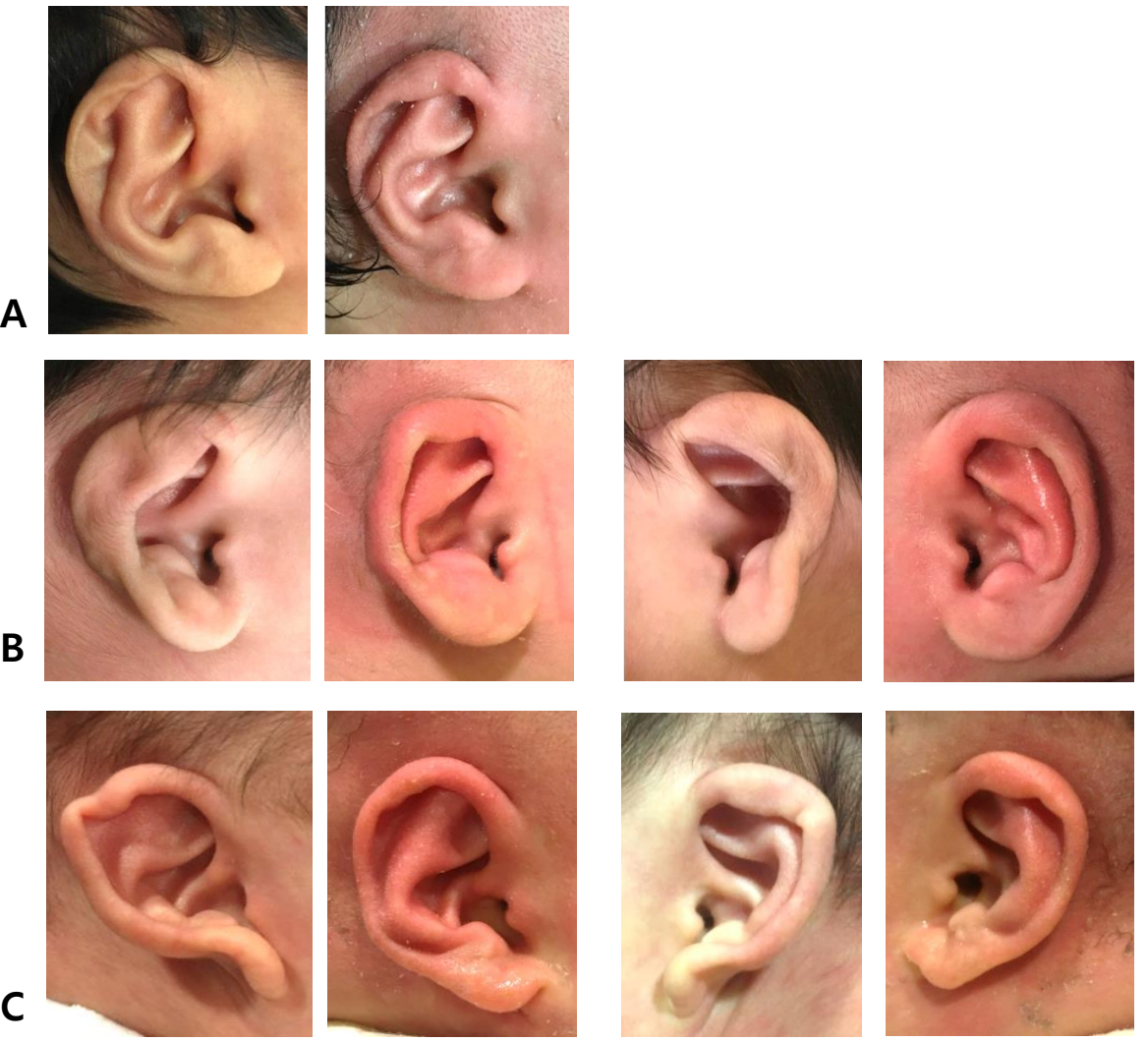

Figure 2. Presented are examples of pretreatment (left in each pair) and posttreatment (right in each pair) photographs of a first case with right auricular deformity (A), a second case with both auricular deformities (B), a third case with both auricular deformities (C). Photographs were taken after 2 weeks of treatment.

Table 1. Clinical Data of Cases with Auricular Deformations Undergoing Ear Molding with EarWell System

Case 1

Case 2

Case 3

(1) Type of pretreatment deformity or malformation Helical rim deformity (right Mixed ear of lidding ear and Helical rim deformity (right ear) Cup ear (both ear) ear), Lidding ear (left ear)

(2) The age at the time of initiating treatment

20 days 20 days 20 days

(3) Duration of treatment

14 days

21 days

21 days

(4) Complications

Erosion, exudate, $2 \times 3 \mathrm{~mm}$ ulcer

Eruption of postauricular area, exudate

(5) The posttreatment outcome Corrected Corrected

Corrected

$1 / 3$ 되는 부분에만 1 개 장착하였으며 외이 former는 장착하지 않았 다. 그 후 앞쪽 크래들을 장착하였다. $3 \mathrm{M}$ 테이프로 크래들 윗부분을 ''자로 부착하여 단단히 고정하였다.

3명의 환자 모두 생후 20일째 치료를 시작하였고 교정기간도 2-3 주로 짭았음에도 불구하고 결과가 좋았다(Table 1). 귀 기형의 가족 력은 없었으며 본원에서 출생한 2 명의 환자는 자동화된 청성 뇌간 유발검사로 신생아 청력 선별 검사를 시행한 결과 양쪽 귀 모두 정 상이었으나 타 병원에서 출생한 세 번째 환자는 이상 소견을 보여 3 차 병원 이비인후과 추적 관찰 중이다.

\section{고찰}

신생아 귓바퀴 기형은 흔하며 저절로 호전되지 않는다면 자라는 동안이나 어른이 되어서도 심리적 고통, 행동 장애, 사회적 회피를 경험하게 된다 ${ }^{5,6)}$. 비록 수술적 방법으로 귓바퀴 교정이 가능할 수 있지만 마취의 위험과 출혈, 혈종, 염증, 기형이 남는 등 수술로 인한 부작용 및 높은 비용이 발생한다 ${ }^{7)}$. 따라서 비정상적인 귓바퀴 모양 을 가지고 태어난 환자를 위해 신생아 기간 동안 치료가 가능한 비 침습적인 방법인 귓바퀴 교정기의 효과에 대해 많은 연구가 진행되 
어 왔다 ${ }^{1,8-14)}$

생후 며칠 동안, 귓바퀴 연골은 순환하는 모성 에스트로겐으로 인 해 특이하게도 가소성을 가지고 있다). 이 호르몬은 생후 3 일에 가 장 높으며 그 후 6 주 동안 기준치로 돌아오게 된다 ${ }^{8)}$. 연골의 중요한 구성 요소인 히알루론산(hyaluronic acid)이 순환하는 에스트로겐에 의해 상승되며 또한 신생아 귀의 가단성에 중요한 역할을 한다는 가 설이 있다 ${ }^{1,912)}$. 따라서 비수술적인 교정 방법으로 귓바퀴 기형을 치 료하기 위해서는 생후 초기에 짧은 시간 안에 시행해야 한다 ${ }^{7,9,13)}$. 이 러한 이유로 생후 6 주 후 신생아에게 귀 교정기를 사용할 경우 결과 가 좋지 않다.

귓바퀴 변형(deformation)의 종류는 돌출 귀(prominent ear), 접 힌 귀(lidding ear), 이갑개 각 기형(conchal crus deformity), 스탈씨 귀(stahl's ear), 귓바퀴 테두리 이상(helical rim deformity)으로 나누 어지며 귓바퀴 기형(malformation)은 수축 귀(constricted ear)와 매 몰 귀(cryptotia), 소이증(microtia)으로 나뉘며 컵 모양 귀(cup ear) 는 수축 귀의 한 형태로 본다 ${ }^{13}$. 본 저자들은 귓바퀴 테두리 이상, 컵 모양과 접힌 귀 모양이 있는 혼합형 귀, 접힌 귀 기형을 가지고 있는 3 명의 환자들의 5 개 귓바퀴 기형을 대상으로 EarWell System 귀 교 정기를 시행하였다. 이 교정기는 위에 언급한 대부분의 귓바퀴 변형 과 기형들의 치료가 가능하지만 외이의 부분적 결손이 있거나 소이 증은 치료가 어렵다.

본 저자들은 귀 교정기인 EarWell System을 사용하여 생후 20일 경 치료를 시작하였다. 출생 후 14일 이전에 Earwell System으로 교 정 시 $90 \%$ 이상의 성공률을 보인다고 보고하고 있으나 대부분의 보 호자들은 저절로 정상 귀 모양으로 돌아올 것이라 기대하고 있기 때 문에 실제로 그 이전에 치료를 시작하기가 쉽지 않았다고. 교정 기간 은 4-6주 동안 시행하고 2주에 한번 외래에서 교정 과정 및 피부 부 작용을 점검할 것을 권고하고 있다. 그러나 Doft 등의 연구에서는 96 명의 환자를 대상으로 158 개의 귓바퀴 기형들을 생후 2 주 이내, 평균 2주 동안 치료한 결과 $96 \%$ 에서 정상귀로 교정되었다고 보고 하였닥. 본 연구의 교정 기간도 2-3주로 짧았으며 모두 정상 귀 모 양으로 교정이 된 것을 확인하였다. 3 명 중 2 명의 환자에서 발적, 진 물, 궤양과 같은 피부 질환이 발생하였고 1 명의 환자는 부작용 없이 교정되었다. 본 연구에서는 적어도 1 주일에 한 번 외래 추적 관찰을 통해 부작용을 확인하였다.

EarWell System은 간단하고 빨리, 통증 없이, 비수술적으로 신 생아 귓바퀴 기형을 치료할 수 있으며 다른 교정 방법보다 효과가 좋고 더 오랜 기간 동안 효과를 지속할 수 있는 것으로 알려졌닥. Daniel 등의 연구에서 치료 결과를 보면 혼합 기형과 유전성 귀 기형 을 제외하고 $90 \%$ 이상의 환자에서 귓바퀴 기형이 교정되었고 ${ }^{4)} \mathrm{Doft}$ 등의 연구에서는 96\%가 교정되었으며 6-12개월 추적관찰로 확인했 음을 보고하였닥. 또한 시술 시 통증이 없기 때문에 마취, 진정 혹 은 어떠한 약물도 필요하지 않다. 하지만, 시술 과정에서 피부 질환
과 같은 부작용이나 교정 실패가 있을 수 있으므로 신생아의 부모에 게 충분히 설명하고 동의서를 작성한 후 숙련된 의사에 의해 치료를 시작해야 한다. 귓바퀴 기형은 미용상의 문제로 생각할 수 있지만 환자 본인이나 부모의 신체적 혹은 정신적 발달에 부정적인 영향을 미칠 수도 있음을 간과해서는 안되며 수술적인 방법보다 덜 침습적 이고 실용적이며 안전한 방법이 있다는 것을 알고 있어야 한다.

1980년대 이래로 금속 클립과 플라스틱 테이프(3M, St Paul, Minnesota, USA), 땜납 와이어와 테이프(Steri-Strip), Putty Soft, a vinyl polysiloxane impression material과 테이프(Steri-Strip) 등 여러 종류 의 부목, 스텐트, 교정 재료를 사용한 비수술적인 귓바퀴 교정 방법 이 제시되고 있다 ${ }^{7,812)}$. 하지만 대부분 본 연구와 같이 증례 연구이기 때문에 각 방법에 대한 성적이나, 장단점, 치료 범위의 차이를 알아 보기 위해서는 잘 설계된 대규모 무작위 대조 연구가 필요하며 명확 한 판단을 위해 오랜 기간 추적관찰이 필요할 것으로 생각된다.

\section{REFERENCES}

1) Byrd HS, Langevin CJ, Ghidoni LA. Ear molding in newborn infants with auricular deformities. Plast Reconstr Surg 2010; 126:1191-200.

2) Smith W, Toye J, Reid A, Smith R. Nonsurgical correction of congenital ear abnormalities in the newborn: case series. Paediatr CHILD Health 2005;10:327.

3) Merlob P, Eshel Y, Mor N. Splinting therapy for congenital auricular deformities with the use of soft material. J Perinatol 1994;15:293-6.

4) Daniali LN, Rezzadeh K, Shell C, Trovato M, Ha R, Byrd HS. Classification of newborn ear malformations and their treatment with the EarWell infant ear correction system. Plast Reconstr Surg 2017;139:681-91.

5) Bradbury ET, Hewison J, Timmons MJ. Psychological and social outcome of prominent ear correction in children. Br J Plast Surg 1992;45:97-100.

6) Horlock N, Vogelin E, Bradbury ET, Grobbelaar AO, Gault DT. Psychosocial outcome of patients after ear reconstruction: a retrospective study of 62 patients. Ann Plast Surg 2005;54:517-24.

7) Doft MA, Goodkind AB, Diamond S, DiPace JI, Kacker A, LaBruna AN. The newborn butterfly project: a shortened treatment protocol for ear molding. Plast Reconstr Surg 2015; 135:577e-83e.

8) Leonardi A, Bianca C, Basile E, Ungari C, Arangio P, Filiaci F, et al. Neonatal molding in deformational auricolar anomalies. Eur Rev Med Pharmacol Sci 2012;16:1554-8.

9) Tan ST, Abramson DL, MacDonald DM, Mulliken JB. Molding therapy for infants with deformational auricular anomalies. Ann Plast Surg 1997;38:263-8. 
10) Zambudio G, Guirao MJ, Sánchez JM, Girón O, Ruiz JI, Gutiérrez MA. Nonsurgical correction of congenital auricular deformities a new method of neonatal molding and splinting. Cir Pediatr 2007;20:139-42.

11) Yotsuyanagi T, Yokoi K, Urushidate S, Sawada Y. Nonsurgical correction of congenital auricular deformities in children older than early neonates. Plast Reconstr Surg 1998;101:907-14.

12) Van Wijk MP, Breugem CC, Kon M. Non-surgical correction of congenital deformities of the auricle: a systematic review of the literature. J Plast Reconstr Aesthet Surg 2009;62:727-36.

13) Ullmann Y, Blazer S, Ramon Y, Blumenfeld I, Peled IJ. Early nonsurgical correction of congenital auricular deformities. Plast Reconstr Surg 2002;109:907-13.

14) Matsuo K, Hirose T, Tomono T, Iwasawa M, Katohda S, Takahashi N, et al. Nonsurgical correction of congenital auricular deformities in the early neonate: a preliminary report. Plast Reconstr Surg 1984;73:38-51. 